\title{
0 raciocínio indutivo em David Hume e Thomas Reid
}

\author{
The inductive reasoning in David Hume and Thomas Reid
}

\author{
Pablo Fernando Campos Pimentel \\ PUC-RS - Brasil \\ pablo_winchester@hotmail.com
}

\begin{abstract}
Resumo: Este artigo busca apresentar de forma concisa o denominado Problema da Indução em David Hume e Thomas Reid. Em Hume, tem-se a recusa profunda de os raciocínios indutivos serem fruto ou resultado de um processo racional. No entanto, em Reid, para além de uma recusa em um processo dito racional, há o apelo àquilo que este chamou de princípios constitutivos da mente humana. Hume apela a um ceticismo epistemológico no qual se viu enredado, ao passo que Reid opta por um caminho diferente, em que o raciocínio indutivo decorre de princípios com os quais a mente humana opera constitutiva e originariamente. Vale ressaltar que a utilização de um pensador como Reid em contraposição a Hume foi feita justamente pelo fato de o contemporâneo Problema da Indução ter sido objeto de reflexão e suscitar, assim, respostas diferentes de ambos filósofos.
\end{abstract}

Palavras-chave: Hume. Reid. Indução. Princípios.

\begin{abstract}
This article seeks to present in a concise way the so-called Problem of Induction in David Hume and Thomas Reid. In Hume, one has the profound refusal that inductive reasoning is the result of a rational process. However, in Reid, apart from a refusal in a so-called rational process, there is the appeal to what he called the constitutive principles of the buman mind. While Hume appeals to an epistemological skepticism in which be has become entangled, Reid chooses a different path in which the inductive reasoning stems from principles with which the human mind operates constitutively and originally. It is noteworthy that the use of a thinker like Reid in opposition to Hume was made, precisely because the contemporary Problem of Induction was the object of reflection and gave rise to different answers on the part of both philosophers.
\end{abstract}

Keywords: Hume. Reid. Induction. Principles.

\section{Introdução}

Esta investigação tem como cerne o Problema da Indução em David Hume (1711 - 1776), filósofo britânico, nascido na Escócia, conhecido, em grande parte, por seu ceticismo filosófico, e Thomas Reid (1710 - 1796), nascido em Strachan, Aberdeenshire, fundador da escola escocesa da filosofia do senso comum. 
Este intento tem o objetivo de apresentar à comunidade de investigação uma "justificação" da indução ou a forma como David Hume e Thomas Reid buscaram justificar a inferência ou raciocínio indutivo como fonte confiável de conhecimento.

O problema da indução está em que, segundo Hume:

A razão jamais pode nos mostrar a conexão entre dois objetos, mesmo com a ajuda da experiência e da observação de sua conjunção constante em todos os casos passados. Portanto, quando a mente passa da ideia ou impressão de um objeto à ideia de outro objeto, ou seja, à crença neste, ela não está sendo determinada pela razão, mas por certos princípios que associam as ideias desses objetos, produzindo sua união na imaginação. (HUME, 2009, p. 121).

A principal crítica feita por Hume quanto ao problema da indução parece ser que, racionalmente, não podemos justificar uma inferência que parte do observado e chega ao não-observado. Mas o que é de fato uma inferência indutiva? Conforme a Routledge Encyclopedia:

[...] uma inferência indutiva é uma inferência a partir de uma premissa da forma "Todo A observado é B" a uma conclusão da forma "Todo A é B". Tais inferências não são dedutivamente validas, isto é, mesmo se a premissa for verdadeira é possível que a conclusão seja falsa, uma vez que os As não observados podem diferir dos observados. No entanto, foi decidido que a premissa pode tornar razoável crer na conclusão, muito embora isso não garanta que a conclusão seja verdadeira. (ROUTLEDGE ENCYCLOPEDIA, 2005, p. 442).

Nessa mesma linha de pensamento, segundo Popper: "[...] independente de quantos casos de cisnes brancos possamos observar, isso não justifica a conclusão de que todos os cisnes são brancos" (2007, p. 28).

É necessário trazer o contexto no qual o problema da indução surge nas obras de Reid, de que forma isso é tratado, que estratégias são pensadas por ele para resolver essa questão e com quem Reid está debatendo naquele momento.

\section{0 problema da indução em David Hume}

Hume nunca utiliza em nenhuma de suas obras o termo raciocínio, inferência ou argumento indutivo. Os termos utilizados pelo filósofo para designar raciocínio indutivo são relação de "causa e efeito", "conexão necessária" e "conjunção constante" quando se refere às "questões de fato". Nesse contexto de "causa e efeito", Hume vai indagar a respeito de como podemos raciocinar em termos de causa e efeito, sendo que, logicamente, pensar o oposto não implica contradição alguma.

Temos, no entanto, de situar o leitor em relação à ordem em que aparecem os argumentos de Hume com respeito ao tópico da indução, ou seja, apresentaremos, primeiro, algumas breves passagens expostas em seu Tratado e, depois, outras passagens em sua Investigação. 
A dúvida de Hume em relação à racionalidade da indução parece repousar sobre a questão de como podemos justificar de maneira racional uma inferência acerca de um objeto observado pela experiência de algo que escapa ao alcance da observação, ou seja, algo que escapa ao testemunho dos sentidos ou da linguagem.

Conforme Hume:

É apenas pela experiência, portanto, que podemos inferir a existência de um objeto da existência de outro. [...] Tendo já visto que a transição que fazemos de uma impressão, presente à memória ou aos sentidos, para a ideia de um objeto que denominamos causa ou efeito está fundada na experiência passada e em nossa lembrança de sua conjunção constante, a próxima questão é: a experiência produz a ideia por meio do entendimento ou da imaginação? É a razão que nos determina a fazer a inferência, ou uma certa associação e relação de percepções? Se fosse a razão, ela o faria com base no princípio de que os casos de que não tivemos experiência devem se assemelhar aos casos de que tivemos experiência, e de que o curso da natureza continua sempre uniformemente o mesmo. (HUME, 2009, p. 116-118).

Para Hume: "A razão jamais pode mostrar a conexão entre dois objetos, mesmo com a ajuda da experiência e da observação de sua conjunção constante em todos os casos passados" (2009, p. 121). Portanto, aquilo que nos faz inferir um objeto a partir de outro não é a razão, mas outra coisa, e essa outra coisa é chamada de princípio de causalidade ou relação de causa e efeito.

A partir da Investigação, uma pergunta muito importante que pode ser feita aqui é a seguinte: Qual é a dificuldade enfrentada por Hume no que tange à indução? Essa pergunta tem a ver com os segundos objetos da razão humana, ou seja, as questões de fato das quais temos tratado e que podem ser respondidas primariamente com a seguinte afirmação conforme Hume:

Os fatos [...] não são determinados da mesma maneira, nem nossa evidência de sua verdade por maior que seja é de natureza igual à precedente. O contrário de um fato qualquer é sempre possível, pois, além de jamais implicar uma contradição, o espírito o concebe com a mesma facilidade e distinção como se ele estivesse em completo acordo com a realidade. Que o sol não nascerá amanhã é tão inteligível e não implica mais contradição do que a afirmação que ele nascerá. [...] Portanto, deve ser assunto digno de nossa atenção investigar qual é a natureza desta evidência que nos dá segurança acerca da realidade de uma existência e de um fato que não estão ao alcance do testemunho atual de nossos sentidos ou do registro de nossa memória. (HUME, 1999, p. 48).

De acordo com Salmon: "A profunda crítica da indução, feita por Hume, começa com uma questão simples e aparentemente inocente: como adquirimos conhecimento do inobservado?" (2010, p. 176). Portanto, aqui é delineada a primeira 
crítica de Hume ao "problema da indução", ou seja, como podemos adquirir conhecimento a partir daquilo que ainda não experimentamos?

De acordo com Hume: "[...] nem é razoável concluir, apenas porque um evento em determinado caso precede outro, que um é a causa e o outro, o efeito. [...] Não há base racional para inferir a existência de um pelo aparecimento do outro" (1999, p. 60-61). Temos aqui a crítica quanto à não justificação epistêmica para uma crença aos moldes do raciocínio indutivo. E, também, a recusa por parte de Hume ao Princípio da Uniformidade da Natureza, o qual afirma que o futuro se assemelhará ao passado.

Há um princípio que faz com o que o homem extraia uma conclusão com base na experiência, quando do aparecimento de um objeto se dê o surgimento de seu correlato, que afirmou Hume: "Este princípio é o costume ou o hábito" (1999, p. 61).

Portanto, esse princípio por trás da experiência é o costume, a saber, todas as conclusões que podemos extrair a partir da experiência do observado ao não observado serão por força do hábito ou do costume, dos quais não se pode prescindir.

Para Hume: "Sem a influência do costume, ignoraríamos completamente toda questão de fato que está fora do alcance dos dados imediatos da memória e dos sentidos" (1999, p. 63). Fica patente que o costume e o hábito são imprescindíveis para o agir e para o esperar cotidianos.

De acordo com Popper:

Hume interessava-se pela situação do conhecimento humano ou, como poderia ter dito, por indagar se alguma de nossas crenças - e qual delas - poderia ser justificada por razões suficientes.

Levantou ele dois problemas: um problema lógico $(\mathrm{Hl})$ e um problema psicológico (Hps).

[...] O problema lógico de Hume é:

$\mathrm{Hl}$ - Somos justificados em raciocinar partindo de exemplos (repetidos), dos quais temos experiência, para outros exemplos (conclusões), dos quais não temos experiência?

A resposta de Hume a $\mathrm{Hl}$ é: Não, por maior que seja o número de repetições.

[...] O problema psicológico de Hume é:

Hps - Por que, não obstante, todas as pessoas sensatas esperam, e creem que exemplos de que não tem experiências conformarse-ão com aqueles de que têm experiência? Isto é: Por que temos expectativas em que depositamos grande confiança?

A resposta de Hume é: Por causa do "costume ou hábito"; isto é porque somos condicionados pelas repetições e pelo mecanismo da associação de ideias, mecanismo sem o qual, diz Hume, dificilmente poderíamos sobreviver. (POPPER, 1975, p. 15-16).

É por isso que, de acordo com Neiva (2013, p. 72):

Podemos supor que a experiência nos proporcionou um número abundante de repetições entre dois eventos A e B. Basta que um 
deles seja objeto de nossa experiência em mais uma instância individual para que a inferência seja engendrada pelo recurso psicológico do costume ou hábito: este se torna efetivamente um procedimento condicionado do pensamento, sobretudo em relação aos padrões que se repetem com maior frequência e menor número de contraexemplos. (NEIVA, 2013, p. 72).

Deste modo, não foram poucos os pensadores a chegarem à mesma conclusão, a saber, as inferências indutivas em Hume são guiadas pelo hábito ou costume.

\section{Thomas Reid: 0 argumento em "An inquiry into the human mind on the principles of common sense"}

Nesta primeira grande obra de Reid, constrói-se, em certo sentido, uma epistemologia do testemunho. Há na epistemologia testemunhal de Reid a reivindicação aos chamados "primeiros princípios", princípios com os quais, segundo Reid, todos operam, tanto nas questões simples do cotidiano quanto nas questões complexas do conhecimento humano.

Esses "primeiros princípios", também denominados de princípios do senso comum, no capítulo em que se trata sobre a percepção e o testemunho, são, primeiramente, denominados por Reid como "princípios gerais da mente humana".

No Inquiry, são nos informados, em particular, três princípios, dos quais dois deles aparecem abaixo, conforme as palavras de Lehrer:

Existem dois princípios originais que são essenciais à nossa instrução na linguagem. Um é o princípio da veracidade, o outro é o princípio da credulidade. O primeiro é "uma propensão a falar a verdade, e usar os sinais da linguagem, de modo a transmitir os nossos sentimentos reais". O segundo é uma "disposição a confiar na veracidade de outros, e acreditar no que eles nos falam". (Lehrer, 2002, p. 75).

Assim, aparecem dois importantes princípios gerais da mente, o princípio da veracidade e o princípio da credulidade. Segundo as palavras do próprio Reid, embora o ser humano possua a capacidade de mentir ao seu semelhante e a disposição de desconfiar do testemunho dos outros, o instinto natural é falar a verdade e crer no que nos é falado.

O terceiro princípio a ser levantado por Reid é o "princípio indutivo" (inductive principle), que pode ser definido como nas palavras de Lehrer:

Primeiro de tudo, "quando encontramos duas coisas sendo constantemente unidas no curso da natureza, a aparição de uma delas é imediatamente seguida pela concepção e crença da outra". Isto é o princípio indutivo. Crianças pequenas procedem de acordo com este princípio primeiro ao uso da razão, e, portanto, isto é "o efeito do instinto, não da razão" (p.198). O princípio indutivo corresponde ao princípio da credulidade e pressupõe um princípio análogo ao princípio da veracidade. 
Este é o princípio da regularidade na natureza. O princípio indutivo é o princípio do raciocínio indutivo bem como da percepção adquirida. (LEHRER, 2002, p.76).

Portanto, o princípio indutivo é aquele que nas palavras de Thomas Reid é definido como sendo o "princípio da uniformidade da natureza", a saber, a constatação das regularidades dos eventos da natureza, gerando assim a crença de que a natureza será no futuro como o foi no passado.

Pode-se concluir, portanto, em torno dessa primeira obra de Reid, o Inquiry, o seguinte: i) existem princípios do senso comum com os quais o homem opera cotidianamente; ii) esses princípios regem intuitivamente a ação e a conduta humanas; iii) esses princípios do senso comum servem, para Reid, como justificadores epistêmicos ou como afirmou Alston (1985) são princípios básicos epistemológicos; e iv) sem tais princípios a crença no testemunho dado pela natureza através dos sentidos e o testemunho dado pelo homem através da linguagem seriam impossíveis, e, em última instância, o homem não teria meios possíveis de instruir-se.

Os três princípios constitutivos da mente supracitados são, segundo Reid, princípios do senso comum, com os quais o homem opera, desde as coisas mais comuns da vida até os assuntos mais complexos.

Nesse ínterim, o raciocínio indutivo se desenvolve a partir de qualquer dos três princípios então abordados, levando-nos a interpretar que, tanto o princípio da veracidade, da credulidade ou o princípio indutivo envolvem uma crença não baseada na razão, mas em princípios constitutivos de nossa natureza, que, a partir da aparição do sinal, gera a crença e a concepção na coisa por ele significada. Pois, quando falamos algo, esperamos que o nosso ouvinte entenda nossa linguagem, e nossas afirmações tendem, pelo princípio da veracidade, a serem verdadeiras. Pelo princípio da credulidade, tomamos por verdadeiro aquilo que nos é testemunhado por nossos semelhantes e, pelo princípio indutivo, tomamos como verdadeiro o testemunho dado pela natureza por meio da conjunção constante de coisas no tempo passado às nossas faculdades naturais.

Sendo assim, qualquer desses princípios carrega em suas afirmações crenças acerca do mundo e explicam de maneira razoável a formação de crenças acerca das informações recebidas pelo testemunho humano - dado pela linguagem artificial e das informações recebidas - e pelo testemunho da natureza - dado pelos sentidos nas percepções adquiridas.

Segundo Reid, ambos os testemunhos, através dos princípios explicitados, conduzem à verdade, quando devidamente iluminados pela luz da observação e experiência.

Logo, fica evidente, porque é afirmado por Lehrer: "O princípio indutivo é o princípio do raciocínio indutivo, bem como da percepção adquirida" (2002, p. 76). Pois, nas percepções adquiridas, os sinais são, de acordo com Reid:

[...] ou sensações ou coisas que percebemos por meio das sensações. A conexão entre o sinal e a coisa significada é estabelecida pela natureza: e nós descobrimos essa conexão pela experiência; mas, não sem a ajuda de nossas percepções originais, ou daquelas que já adquirimos. Depois que essa 
conexão é descoberta, o sinal, assim como na percepção original, sempre sugere a coisa significada e cria a crença nela. (REID, 2000, p. 191).

Sendo que o princípio indutivo corresponde ao princípio de regularidade da natureza, que pode ser explicado pelas próprias palavras de Reid:

Todo nosso conhecimento da natureza, além de nossas percepções originais, é obtido pela experiência, e consiste na interpretação dos sinais naturais. A constância das leis da natureza conecta o sinal com a coisa significada, e, pelo princípio natural agora explanado, confiamos na continuidade das conexões que a experiência tem descoberto; e, assim, a aparição do sinal, é seguida pela crença da coisa significada. (REID, 2000, p. 198).

A seguir constatamos algumas afirmações bastante firmes com respeito às conjunções constantes de duas coisas no curso continuo da natureza, a saber, de acordo com Faller e Pich:

[...] nas percepções adquiridas, não é somente o caso que "a conexão entre o sinal e a coisa significada é estabelecida pela Natureza"; ela, antes, precisa ser descoberta através de "experiência" e "indução". Ora, trata-se, aqui, de percepções ou conteúdos mentais perceptuais que se explicam pela constante conjunção de duas coisas, no curso da natureza, tal que uma primeira se torna sinal de outra e autoriza, assim, o conhecimento de sua conjunção na forma de espontânea concepção e crença. Nesse caso, a experiência e o mecanismo de indução funcionam como percepção de contínua conjunção no fluxo do tempo (passado, presente e futuro) [...] O pressuposto mental instintivo (não derivado da razão) ou a "presciência instintiva das operações da natureza", "muito parecida com aquela presciência de ações humanas que nos faz confiar no testemunho das nossas criaturas-semelhantes", é o princípio pelo qual cremos e esperamos a continuidade ou regularidade do curso da natureza, bem como das conexões que foram, no passado, observadas: "É por esse princípio geral de nossa natureza que, quando duas coisas têm estado conectadas no tempo passado, a aparição de uma produz a crença da outra".

[...] A constância das leis da natureza, que a experiência nota, somada à confiança na continuação das ditas conexões como princípio que fundamenta a ligação de um mesmo sinal com uma mesma coisa e, em seguida, de um sinal com outro, permite conhecer a natureza e o mundo na forma de crenças que têm suporte em raciocínio indutivo e por analogia. (FALLER e PICH, 2014, p. 142).

A supracitada passagem ilustra claramente a capital importância da "experiência" e do "mecanismo indutivo" como percepção do fluxo contínuo do tempo e das coisas constatadamente unidas nessa passagem de tempo. 
O tratamento dado por Reid no Inquiry parece findar na questão epistêmica do ser humano enquanto possuidor de determinados princípios que regem sua ação e expectativas frente a seus semelhantes. E, desse modo, o ser humano opera constitutivamente em relação às expectativas que forma tanto quanto à natureza; quanto aos seus semelhantes, com princípios que lhe garantem a compreensão da linguagem usada por si mesmo e os semelhantes, quando da utilização de sinais a expressar coisas por eles significados; quanto da natureza a nos informar seus efeitos regulares a partir de sua constância constatada através do estudo de suas leis contínuas e uniformes.

\section{Thomas Reid: as alegações em "Essays on the intellectual powers of man" sobre raciocínio, raciocínio provável e evidências prováveis}

Nos Essays, é exposta uma definição simples, porém interessante, acerca de raciocínio (reasoning). Conforme Reid:

Raciocínio é o processo pelo qual passamos de um juízo a outro que é a consequência dele. Conformemente, nossos julgamentos são distinguidos em intuitivos, que não são baseados em qualquer julgamento precedente, e discursivos, que são deduzidos a partir de algum julgamento precedente por raciocínio.

Em todo raciocínio, portanto, deve haver uma proposição inferida, e uma ou mais a partir da qual é inferida. E este poder de inferir, ou extrair uma conclusão, é apenas outro nome para raciocínio; a proposição inferida sendo chamada a conclusão, e a proposição, ou proposições das quais é inferida, as premissas. (REID, 2002, p. 542).

Temos uma definição, embora bastante simples, muito objetiva e correta do passo-a-passo do que é um argumento, ou seja, de um processo de raciocínio, por parte de Reid. Este não se demora a distinguir os raciocínios em prováveis e demonstrativos. Nos raciocínios prováveis a conexão entre as premissas e a conclusão não são necessárias. Desse modo, de acordo com Reid: "De todas as coisas criadas, a existência, os atributos, e consequentemente as relações resultantes daqueles atributos, são contingentes. Dependem da vontade e poder daquele que as fez. São questões de fato e não admitem demonstração" (2002, p. 545).

Segundo Lehrer: "Demonstração não admite graus, enquanto raciocínio provável, sim" (2002, p. 172). Pois, será inserido nos raciocínios que os juízos terão vez, os primeiros princípios das verdades contingentes, que são um tipo de primeiro princípio, a saber, aqueles primeiros princípios que se aplicam às questões de fato, para usar uma linguagem humeana, e à experiência, usando um termo de Reid.

Desse modo, teremos o raciocínio dividido em duas categorias: os raciocínios demonstrativos, que têm a ver com os primeiros princípios das verdades necessárias - um exemplo disso são os raciocínios relativos à lógica e à matemática-; e os raciocínios prováveis, que são aqueles que se aplicam aos primeiros princípios das verdades contingentes - um exemplo disso são os raciocínios aplicados às percepções sensórias. 
Poderíamos afirmar, sem prejuízo, que o raciocínio é um poder ativo na mente humana do qual, munida de juízos, sejam intuitivos ou baseados em argumentos, extraímos conclusões acerca de questões que dizem respeito à natureza, e por isso são meramente prováveis, ou a questões demonstrativas, e referem-se apenas a axiomas, como regras gerais.

Segundo Lehrer:

Raciocínio demonstrativo é distinguido de raciocínio provável. Raciocínio provável, que contém nossos raciocínios sobre questões de fato, é falível, como são todas as nossas faculdades, mas pode produzir conclusões que são certas. A combinação da concessão de que somos falíveis nos juízos com o assentimento que nossos juízos podem, mesmo assim, estar certos é uma doutrina fundamental da epistemologia e psicologia de Reid. A singularidade da doutrina pode ser considerada por notar que para Reid o que é maximamente razoável é certo. Certeza não é perfeição. É nosso mais alto, embora falível, nível de realização cognitiva. (LEHRER, 2002, p. 171).

Importante perceber que para Reid, mesmo que sejamos falíveis em tudo, podemos produzir conclusões que sejam certas, pois, aquilo que é altamente razoável é certo, visto que, como citado, certeza não é perfeição. Portanto, novamente aparece aqui aquilo que já vimos, pois, que embora nossas faculdades sejam falíveis, elas tendem a produzir verdade e não são falaciosas, logo, nossas faculdades são confiáveis, e, por esse motivo, Reid é tido como sendo um confiabilista.

No capítulo III, Sobre o raciocínio provável, do ensaio VII, Sobre o raciocínio, Reid reserva um espaço para as considerações acerca do tipo de raciocínio que hoje tratamos por raciocínio indutivo, em grande parte. Embora este utilize o termo "inductive" vez ou outra, aos nossos propósitos não chamará os raciocínios (reasonings) como contemporaneamente o fazemos, ou seja, separando-os em dedutivos ou indutivos para estudo.

Para Reid:

A força de um raciocínio provável, na maior parte, não depende de qualquer argumento, mas de muitos, que unem suas forças, e conduzem à mesma conclusão. Qualquer um deles seria insuficiente para convencer; mas o todo tomado junto pode ter uma força que é irresistível, tanto que desejar mais evidência seria absurdo. [...] Em todo ramo de conhecimento real deve haver primeiros princípios dos quais a verdade é conhecida intuitivamente, sem raciocínio, seja provável ou demonstrativo. Eles não são fundados no raciocínio, mas todo raciocínio é fundado neles. (REID, 2002, p. 556).

Passemos, no entanto, a seguir, às considerações com respeito às evidências prováveis - evidências essas que fornecem ao raciocínio mais força para sua conclusão. Essa consideração será de suma importância pelo fato de que teremos aqui outro argumento em favor daquilo que vimos discutindo e deliberando 
desde o início deste trabalho, a saber, de que modo Reid possivelmente justifica o problema da indução, ou seja, de que modo Reid justifica o nosso raciocínio ou inferências indutivas?

No seguimento desse tópico Reid trará uma questão que merece uma abordagem clara, o que é evidência provável? Essa pergunta é levantada pelo fato deste trazer para a discussão o debate em torno do significado de evidência provável. ${ }^{1}$ Quanto ao que é certo e provável é dito isto, a saber, que o que é certo é mais que provável, ao passo que o que é apenas provável não é certo. ${ }^{2}$

No entanto, coisas são afirmadas sobre o entendimento dos filósofos acerca de evidência provável e evidência demonstrativa, a saber, de acordo com Reid (2002, p. 557): "Os filósofos consideram evidência provável, não como um grau, mas como uma espécie de evidência que é oposta, não à certeza, mas a outra espécie de evidência, chamada demonstração". Ao passo que, segundo Reid, "Evidência demonstrativa não tem graus, mas evidência provável, tomada no sentido filosófico, tem todos os graus, do menor ao maior, que chamamos de certeza" (2002, p. 557).

Desse modo, conforme Reid:

Todo grau de evidência percebido pela mente produz um grau proporcional de assentimento ou crença. O julgamento pode estar em perfeita suspensão entre duas opiniões contraditórias, quando não há evidência para qualquer delas, ou igual evidência para ambas.

[...] A crença é misturada com a dúvida, mais ou menos, até que cheguemos ao mais alto grau de evidência, quando toda dúvida desaparece, e a crença é firme e imóvel. Este grau de evidência, o mais alto que as faculdades humanas podem alcançar, chamamos certeza. (REID, 2002, p. 557).

A partir disso, Reid distinguirá a "evidência provável" em alguns tipos, a saber: (i) do testemunho humano, sobre o qual a maior parte do conhecimento é construído; (ii) das autoridades daqueles que são bons juízes sobre o assunto em questão; (iii) das quais reconhecemos a identidade de coisas e pessoas de nosso conhecimento; (iv) das que temos das ações e condutas futuras dos homens, a partir de princípios gerais de ação no homem, ou do nosso conhecimento dos indivíduos; (v) das quais coletamos personagens e desenhos dos homens a partir de suas ações, discursos, e outros sinais externos; (vi) das que os matemáticos denominam de probabilidade de chances; e (vii) das quais as conhecidas leis da natureza têm sido descobertas, e os efeitos que têm sido produzidos por elas nas eras primevas, ou que podem ser esperados no tempo por vir. ${ }^{3}$

Passemos à consideração isolada, simplificadamente, de cada um desses tipos de evidências prováveis. Acerca da primeira evidência provável do testemunho humano, Reid diz repousar a fé dos fatos históricos, bem como o julgamento dos tribunais solenes. Uma exposição como exemplo disso é a dada por nosso autor,

1 Cf. REID (1785), 2002, p. 557.

2 Ibid, p. 557.

3 Ibid, p. 560. 
pois, para Reid: "Quando há um acordo de muitas testemunhas, em uma grande variedade de circunstâncias, sem a possibilidade de uma combinação prévia, a evidência pode ser igual àquela da demonstração" (2002, p. 558).

O segundo tipo de evidência provável repousa sobre a autoridade concedida aos experts em sua área e especialidade, quando não estamos aptos a emitir julgamentos que extrapolem nosso campo de atuação, e, desse modo, devemos aplicar peso à evidência de outros que são autoridades naquilo que julgam.

Um terceiro tipo de evidência provável é aquele sobre o qual a identidade de coisas e pessoas é determinado nos tribunais de justiça. E o quarto tipo de evidência provável é aquele que fala da previsão das ações e condutas humanas futuras, em que, dadas certas circunstâncias, o homem agirá no futuro de acordo com o que lhe acontecer no presente.

O quinto tipo de evidência provável é aquele que trata das características coletadas do homem a partir de suas ações, discursos e outros sinais externos, o qual afirma que é a partir de sinais externos que devemos extrair todo conhecimento que pudermos alcançar das características humanas.

O sexto tipo de evidência provável é o que se chama de probabilidade das chances. Conforme Reid: "[...] a doutrina das chances tem fornecido um campo de raciocínio demonstrativo de grande extensão, embora os eventos sobre os quais este raciocínio é empregado não sejam necessários, mas contingentes, e não sejam certos, mas prováveis" (2002, p. 560).

O sétimo tipo de evidência provável é aquele que torna conhecidas as leis da natureza, seus efeitos produzidos no passado e o que se pode esperar em relação ao futuro. ${ }^{4}$ Segundo Reid: "Deduzimo-las apenas a partir dos fatos que caem dentro da nossa observação, ou são propriamente comprovados por aqueles que os têm observado" (2002, p. 560). Portanto, esse tipo de evidência provável versará sobre a observação das leis da natureza sobre o que foi e sobre o que se deve esperar futuramente.

De acordo com Reid, o conhecimento que o filósofo alcança e possui das leis da natureza difere das pessoas comuns não pelos primeiros princípios sobre os quais é fundado, mas na extensão e exatidão, pois, ele coleta cuidadosamente os fenômenos que conduzem à mesma conclusão e os compara com aqueles que parecem contradizê-lo ou limitá-lo. ${ }^{5}$

Desses sete tipos de evidências prováveis, poderíamos aduzir que as evidências prováveis que mais contribuem para o entendimento da indução são o primeiro tipo, sobre o testemunho humano, e o segundo tipo, que é aquele pelo qual as conhecidas leis da natureza têm sido descobertas e os efeitos que têm sido produzidos por elas em eras anteriores ou que podem ser esperados no tempo por vir.

Pode ser feita a seguinte pergunta, a saber, de que modo esses tipos de evidência provável podem contribuir para o nosso entendimento da indução ou para a justificação de inferências indutivas do tipo "todo A observado é B, a todo A é B"?

A isso convidamos o leitor a fazer conjuntamente conosco uma breve análise desses tipos de evidências prováveis e fazer algumas constatações.

$\begin{array}{ll}4 & \text { Ibid, p. } 560 . \\ 5 & \text { Ibid, p. } 561 .\end{array}$

Cognitio, São Paulo, v. 18, n. 2, p. 243-258, jul./dez. 2017 
Podemos utilizar o exemplo exposto por Reid. Segundo Lehrer: "Quando há acordo no testemunho de muitas testemunhas em uma grande variedade de circunstâncias sem a possibilidade de prévia conspiração, 'a evidência pode ser igual àquela da demonstração'” (2002, p. 174). Desse exemplo poderíamos tirar a seguinte conclusão, visto que todas as testemunhas observadas no caso afirmaram que é o caso que x, ou seja, "Todo A observado é B", e, com base nos dados conhecidos, se aparecesse uma nova testemunha para o caso em questão, a inferência que faríamos com base nos casos observados seria que "Todo A é B". A evidência provável seria a de que esse novo testemunho teria uma forte ou irresistível propensão a ser idêntico aos casos observados. Ao que é afirmado por Lehrer (2002) que o consenso pode, sob condições apropriadas, produzir certeza.

Quanto ao segundo tipo de evidência provável, a saber, "aquela pela qual as conhecidas leis da natureza têm sido descobertas e os efeitos que têm sido produzidos por elas em eras anteriores ou que podem ser esperados no tempo por vir", Lehrer afirma: "Reid diz que podemos deduzir as leis da natureza a partir da observação, mas ele usa a palavra 'deduzir' com o mesmo significado da palavra "inferir'” (LEHRER, 2002, p. 174-175).

O que parece encaixar no fato de que o tipo de evidência provável referida produza boa razão para crer que inferências indutivas se justificam é que, para Lehrer: "Embora todas pessoas alcancem conhecimento das leis da natureza como efeito de um princípio indutivo inato de sua constituição, o filósofo obtém conhecimento de maior extensão e com maior exatidão por reduzir fatos observados a regras gerais" (LEHRER, 2002, p. 175).

A partir disso, Lehrer aborda um trecho no qual afirma justamente isso que acabou de ser dito, a saber, reduzir fatos observados a regras gerais é, ao menos, plausível ao nosso entendimento, pensar no formato da inferência indutiva em questão, "Todo A observado têm sido B, a todo A é B". O que também poderíamos dizer é que reduzir fatos observados a regras gerais é, ao menos, num primeiro momento, passar do observado ao inobservado.

\section{Relevância contemporânea do problema da indução}

Apesar deste artigo versar sobre o Problema da Indução em David Hume e Thomas Reid, faz-se importante apontar a relevância do tema para o debate contemporâneo, apresentando, ao menos, algumas das tentativas de resolução do problema feitas por parte de alguns pensadores como Max Black e David Stove.

A discussão ocorre em torno da justificação epistêmica que teríamos ou não em formar raciocínios indutivos com base no chamado "Princípio de Uniformidade da Natureza”. Segundo pensadores contemporâneos, o problema da indução é o problema de justificar crenças do seguinte tipo:

Premissa: O sol nasceu ontem.

Justifica

Conclusão: O sol nascerá amanhã.

No entanto, por que a crença de que o sol nasceu ontem justifica a crença de que ele nascerá amanhã? Para responder a isso, muitos procuraram reconstruir o argumento que justificaria o princípio da uniformidade da natureza. Na esperança 
de encontrar uma forma em que o princípio da uniformidade não deixasse qualquer dúvida quanto à sua força epistêmica, no entanto, para muitos não foi satisfatório:

Premissa 1: No passado, o futuro se assemelhou ao passado.

Premissa 2: Princípio da Uniformidade da Natureza: O futuro se assemelhará ao passado.

Justifica

Conclusão: No futuro, o futuro se assemelhará ao passado (Princípio da Uniformidade da Natureza).

Esse argumento falha porque se assume aquilo que supostamente se quer mostrar, ou seja, a conclusão (Princípio da Uniformidade da Natureza) aparece como premissa. Essa foi a denominada resposta "Circular" como tentativa de resolver contemporaneamente o problema da indução (BRADLEY, 2015). Pode-se resumir que o observado possa nos dar evidência acerca do não-observado.

Porém, nem tudo está perdido em relação ao argumento circular. Max Black (1971) ofereceu um argumento alternativo à "premissa circular", o argumento "não-premissa circular". Black afirmou que a chave era entender o Princípio da Uniformidade, não como uma premissa, mas como uma regra de inferência. A partir disso, Black nos dá, primeiramente, como exemplo, a regra de inferência dedutiva: afirmar o antecedente (modus ponens) licenciando a inferência seguinte:

A

$\mathrm{A} \rightarrow \mathrm{B}$

Logo B

Agora, no entanto, considere-se a regra de inferência indutiva que, segundo Black, chamaremos "R":

Infere-se R de "no passado, X" para "no futuro, X" (onde X é um tipo de evento). Tomemos isto como o Princípio da Uniformidade reformulado como uma regra de inferência. De acordo com Black é suficiente para o tipo de inferências que queremos. Por exemplo, tomemos $\mathrm{X}=$ nascer do sol.

Premissa: No passado, o sol nasceu.

Justifica

Conclusão: No futuro, o sol nascerá.

Será que estamos justificados em utilizar R como regra de inferência? Black dirá que "No passado, R foi bem-sucedido" justifica "No futuro, R será bem-sucedido". Esta ficou conhecida como Regra de Argumento Circular.

No entanto, a regra de inferência introduzida por Black sofreu objeções, dentre as quais se pode citar, conforme Bradley (2015), que o raciocínio de Black parece-nos permitir inferir que uma regra é confiável apenas pelo seu uso, sem justificação antecedente para isso.

David Stove (1986) buscou resolver o Problema da Indução com o chamado argumento da Amostragem (sampling). Este argumento diz de maneira clara que "As amostras se assemelham ao resto da população". É dito disto que Stove oferece um argumento estatístico de que "uma população provavelmente se assemelhará a uma amostra aleatória tirada dela". Se o argumento estiver correto, poderíamos 
racionalmente inferir de uma "amostra" para a "população", e, assim, teríamos resolvido o problema da indução.

Stove também foi objetado quanto a seu argumento de amostragem. Pois, mesmo se assumirmos ter uma seleção aleatória, isso não é suficiente para justificar crenças razoáveis sobre o não-observado.

As tentativas de solucionar o problema da indução não se esgotam com as apresentadas aqui. Houve uma tentativa de solução semântica ${ }^{6}$. Não podemos deixar de mencionar também que há um Novo Problema da Indução, que não é exatamente semelhante ao clássico discutido desde Hume.

Pelo fato de o problema permanecer sem resolução é que C.D. Broad (1887-1971) chamou a indução de a glória da ciência o escândalo da filosofia (LADYMAN, 2001).

\section{Conclusão}

Retomando a questão central: Como é possível, se é de fato, justificar o raciocínio indutivo em Hume e Reid? Como ambos respondem ao chamado Problema da Indução? Como se pode justificar a racionalidade de determinadas inferências indutivas? Ou, como se pode justificar o raciocínio acerca do não-observado?

De acordo com Hume, não há base racional para inferir que "todos os A's observados são B's”, logo, "todos os A's são B's”. Hume não crê que haja justificação racional para afirmar que a partir dos casos, ou, questões de fato e existência real observados, se possa inferir com certeza uma conclusão com base no princípio da uniformidade da natureza, pois, nem toda uma vida de experiências adquiridas nos daria a ideia ou o conhecimento do poder oculto, pelo qual um dos objetos produziu o outro. ${ }^{8}$

Hume denominou de costume ou hábito o princípio que nos capacita a inferir algo a partir do não-observado. Portanto, o homem produz determinadas conclusões em torno de questões de fato e de existência real não por possuir princípios epistêmicos inatos, mas pelo hábito ou costume arraigados.

No Inquiry aparecem três princípios epistêmicos, chamados por Reid de princípios do senso comum, ou princípios gerais da constituição humana, que são o primeiro - o princípio a uma propensão a falar a verdade e fazer uso da linguagem, de forma a comunicar nossos reais sentimentos -, o segundo - o princípio da disposição de confiar na veracidade de outros, e de crer no que nos dizem. Segundo Reid, um princípio complementa o outro e podem ser denominados como o princípio da veracidade e o princípio da credulidade. O terceiro é o princípio

6 Cf. STRAWSON, 1952. Strawson argumenta que do significado de que o 'sol nasceu ontem' há 'justificação para acreditar que o sol nascerá amanhã'. Portanto, é a ideia de que o princípio da uniformidade da natureza pode ser justificado a priori, em virtude de seu significado.

7 Cf. GOODMAN, 1974. Grue: O novo problema da Indução. Esse novo problema, abordado por Nelson Goodman afirma que existem diversos modos em que o mundo poderia ser uniforme, e por isso, precisaríamos de justificação para crer que o mundo é uniforme de um modo em vez de outro.

8

Cf. HUME, 1999, p. 60-61. 
indutivo, que é descrito como aquele princípio pelo qual os homens creem que o futuro será semelhante ao passado, e que a natureza tem leis fixas, podendo, assim, o homem extrair conclusões acerca do mundo, onde a aparição de um sinal precede o seu efeito ou a coisa por ele significada.

Este último princípio mencionado parece ser o centro acerca de uma defesa do raciocínio indutivo, pois, de acordo com Lehrer: "O princípio indutivo corresponde ao princípio da credulidade e pressupõe um princípio análogo ao princípio da veracidade. Este é um princípio de regularidade na natureza" (2002, p. 76).

Portanto, para Hume a indução radica no que este chamou de costume ou hábito. Ao passo que, contrariamente a Hume, Reid crê ser possível o raciocínio indutivo pelo fato de o ser humano operar com primeiros princípios constitutivos. Por isso, alguns o consideram um fundacionista, por fundar o conhecimento em primeiros princípios. Outros o tomaram como um falibilista, por crer que fontes de conhecimento falíveis podem fornecer justificação para crenças. E outros, ainda, um confiabilista, por depositar total confiança em fontes de conhecimento falíveis.

Como demonstrado, apesar de tantos outros pensadores terem buscado resoluções ao problema de justificar o princípio de uniformidade da natureza, de algo que se verificou no passado, continuar a se verificar no futuro, a questão permanece em aberto.

\section{Referências}

ALSTON, William. Thomas Reid on epistemic principles. In: History of Philosophy Quarterly. University of Illinois Press. v. 2, n. 4, p. 435-452. 1985.

BLACK, M. Problems of Analysis: Philosophical Essays. Westport: Greenwood Press, 1971.

BRADLEY, Darren. A critical introduction to formal epistemology. London/New York: Bloomsbury Academic, 2015.

CRAIG, Edward (Ed.). The shorter Routledge Encyclopedia of Philosophy. LondonNew York: Routledge, 2005.

GOODMAN, N. Fact, fiction, and forecast. Indianapolis: Bobbs-Merrill. 3rd Revised edition, 1974.

HUME, David. Hume: vida e obra. Tradução de Anoar Aiex. São Paulo: Editora Nova Cultura Ltda., 1999.

Tratado da natureza bumana: uma tentativa de introduzir o método experimental de raciocínio nos assuntos morais. Tradução de Débora Danowski. $2^{\underline{a}}$ ed. rev. e ampliada. São Paulo: Editora UNESP, 2009.

LADYMAN, James. Understanding philosophy of science. London: Routledge, 2001. 304p.

LEHRER, Keith. Thomas Reid: the arguments of the Philosophers. London: Routledge, 2002.

NEIVA, André Luiz de A. L. O problema da indução em David Hume. Porto Alegre: Editora Fi, 2013. 
PICH, Roberto H; FALLER, Jacson J. Thomas Reid (1710 - 1796) sobre a natureza e a possibilidade da linguagem. In: Cognitio: revista de filosofia. v. 15, n. 1, p. 125-148, jan/jun. 2014.

POPPER, Karl R. A lógica da pesquisa científica. 13a ed. São Paulo: Cultrix, 2007.

Conbecimento objetivo. Tradução de Milton Amado. Belo Horizonte: Editora Itatiaia Ltda, 1975.

REID, Thomas. An inquiry into the human mind on the principles of common sense (1764). In: BROOKES, D. R. (Ed.). Thomas Reid: - an inquiry into the human mind on the principles of common sense. A critical edition. Edinburgh: Edinburgh University Press, 2000.

. Essays on the intellectual powers of man (1785). In: BROOKES, D. R. Thomas Reid: essays on the intellectual powers of man. A critical edition - The Edinburgh Edition of Thomas Reid. Annotations by Derek R. Brookes and Knud Haakonssen. Introduction by Knud Haakonssen. Pennsylvania: Pensylvannia State University Press, 2002.

SALMON, Wesley. O problema da indução, extraído de os fundamentos da inferência científica. In: BONJOUR, Laurence. Filosofia: textos fundamentais comentados. Consultoria e rev. tec. Maria Carolina dos Santos Rocha e Roberto Hofmeister Pich. 2. Ed. Porto Alegre: Artmed, 2010, p. 175-188.

STOVE, D. C. The rationality of induction. Oxford: Clarendon Press, 1986.

STRAWSON, P. F. Introduction to Logical Theory. London: Methuen, 1952.

Data de envio: 11-09-17

Data de aprovação: 18-10-17 